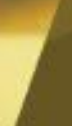

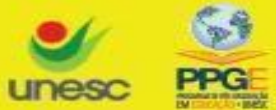

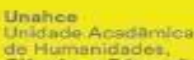 \\ ediunesc
}

Criar Educação, Criciúma, v. 9, №2, Edição Especial 2020.- PPGE - UNESC - ISSN 2317-2452

\section{INVOCAÇÕES DO MITO EM MEIO A PANDEMIA DA COVID-19: A FILOSOFIA ENTRE O FEITICEIRO E PROMETEU}

Lidnei Ventura $^{1}$

\begin{abstract}
Resumo: O presente artigo defende que a situação mundial de Pandemia da Covid-19 tem apresentado, enquanto manifestação das fragilidades humanas, a ressurgência do pensamento mítico em duas direções: o mito do cientista especializado, enquanto alguém que, como Prometeu, roubou o fogo do conhecimento dos deuses e deu aos homens para reconciliá-lo com a natureza; e a regressão ao pensamento mágico clássico, cujo apelo à fé teria também a função de proteger a humanidade do mal. Nesse contexto, a mídia hegemônica aposta sua credibilidade em médicos e especialistas, reiterando sua "neutralidade" ideológica e política. Enquanto as redes sociais sofrem de profunda crise infodêmica, restituindo a função obscura do mito original, que se espalha viralmente pela web. Partindo da Teoria Crítica, o estudo aponta para a importância da filosofia como campo do saber que se opõe às explicações dogmáticas para o complexo momento pandêmico atual.
\end{abstract}

Palavras-chave: Teoria Crítica. Pandemia. Mito.

\section{INVOCATIONS OF THE MYTH IN THE MIDST OF THE COVID-19 PANDEMIC: THE PHILOSOPHY BETWEEN THE SORCERER AND PROMETHEUS}

\begin{abstract}
The present article argues that the world situation of the Covid-19 Pandemic has presented the resurgence of mythical thinking in two directions, as a manifestation of human fragilities: the myth of the specialized scientist as someone who, like Prometheus, stole the fire of knowledge from the gods and gave it to men in order to reconcile them with nature; and the regression to classical magical thought, whose plea to faith would also have the role of protecting humanity from evil. In this context the hegemonic media bet their credibility on doctors and specialists, reiterating their ideological and political "neutrality". Meanwhile, social networks suffer from a profound crisis due to an information overload, restoring the obscure function of the original myth, which spreads virally over the web. Starting from the Critical Theory, the study points to the importance of philosophy as a field of knowledge that opposes dogmatic explanations for the current complex pandemic moment.
\end{abstract}

Keywords: Critical theory. Pandemic. Myth

\footnotetext{
${ }^{1}$ Doutor em Educação (UFSC). Professor Efetivo na Universidade do Estado de Santa Catarina (UDESC). Endereço postal: Rua Antônio Heill, 388. Canasvieiras. Cep: 88054-160. Florianópolis/SC. E-mail:
} 


\section{Introdução}

Em um dos mais importantes livros do século $\mathrm{XX}$, a Dialética do Esclarecimento, Adorno e Horkheimer desnudaram o mito prometeico da ciência moderna. Na sua rigorosa análise sobre a regressão do esclarecimento ao mito, os fundadores da Escola de Frankfurt apontam as pretensões megalomaníacas do sujeito autossuficiente do positivismo, dizendo que "[...] o mito já é esclarecimento e o esclarecimento acaba por reverter à mitologia", pois, no fim das contas, "[...] a submissão de tudo aquilo que é natural ao sujeito autocrático culmina exatamente no domínio de uma natureza e objetividade cegas." (ADORNO; HORKHEIMER, 2006, p. 15).

Esse estudo continua atual, pois a Pandemia da Covid-19 tem manifestado, mundialmente, a ressurgência do pensamento mítico em duas direções: o mito do cientista especialista, enquanto alguém que, como Prometeu, roubou o fogo do conhecimento dos deuses e deu aos homens para apaziguá-los com a fúria da natureza; e o retorno ao pensamento mágico clássico, cujo recurso à fé [crendice, jejum, poções etc.] teria também o poder de proteger a humanidade do mal.

No entremeio das polarizações explicativas da Pandemia, encontra-se 0 pensamento crítico e a reflexão radical, procurando entender as múltiplas determinações dessa realidade.

Como são muitas e complexas as problemáticas levantadas, restringimos a abrangência do presente artigo à exploração da ressurgência do pensamento mítico, próprio em tempos de adversidade, quando o medo da morte e da aniquilação tomam de assalto a racionalidade e aguçam o instinto de sobrevivência, criando deificações diversas. Uma das deidades mais cultuadas que regressa atualmente é mito salvacionista e prometeico da ciência.

Neste contexto, tal como o feiticeiro, que tem por função apaziguar a ira dos deuses, a ciência moderna tende a apaziguar a ira da natureza, que se vê objetificada e estraçalha em fragmentos, assim como a realidade que pretende conhecer. Como no ritual do xamã, cuja repetição recalca o medo das contingências, a lei, a fórmula e o cálculo são as novas máscaras mágicas miméticas e prova do poder sobre a imanência da matéria. A esse respeito, Adorno e Horkheimer (2006, p. 23) ponderam 
que "[...] o princípio da imanência, a explicação de todo acontecimento como repetição, que o esclarecimento defende contra a imaginação mítica, é o princípio do próprio mito".

No caminho do meio se encontra, então, a deslocada e desprestigiada filosofia. No debate mundial acerca da pandemia, acanhadamente é convidada pela grande mídia para opinar sobre o assunto. As grandes redes de televisão apostam sua credibilidade em médicos e especialistas, reiterando sua "neutralidade" ideológica e política, enquanto as redes sociais sofrem de profunda crise infodêmica, restituindo a função mágica do mito original, que se espalha viralmente pela web. No conjunto desse turbilhão, "[...] a enxurrada de informações precisas e diversões assépticas desperta e idiotiza as pessoas ao mesmo tempo." (ADORNO; HORKHEIMER, 2006, p. 14).

A pergunta que fazemos, nesse cenário tragicômico, embora antiga, revelase não somente atual, mas urgente: há algum lugar para a filosofia nesse debate? Ou deveria ser banida, tal como Platão o fez com os poetas da sua República? Ou, quem sabe, interditada, como Comte havia proposto à psicologia na constituição da ciência positiva?

Nos últimos tempos, houve mais uma tentativa de desterro da filosofia, realizada por Jean Piaget, notável psicólogo suíço. Talvez até mesmo tenha sido um de seus porta-vozes mais eloquente, quando alegou razões sobre a Sabedoria e Ilusões da Filosofia, em um de seus inúmeros livros. Portando-se como herdeiro do cientificismo do século XIX, e expressão de um certo ethos antifilosófico, cujos tentáculos de espraiam aos nossos dias, analisaremos alguns aspectos do veto piagetiano às possibilidades do conhecimento filosófico.

Por entendermos, na linha de Karl Jaspers (1971), que a antifilosofia é também uma filosofia, é que pretendemos, neste artigo, vislumbrar uma tábua de salvação para a filosofia na contemporaneidade, evocando em seu favor que qualquer conhecimento humano, incluindo a ciência, está sujeita às intempéries da linguagem, se convertendo, portanto, em um problema hermenêutico.

Para tanto, o plano de reflexão passa pela discussão do papel rigoroso da hermenêutica moderna no escrutínio às pretensões cientificistas de submissão das 
ciências humanas ao método das ciências naturais. Em seguida, passa-se em revista alguns aspectos da proposta epistemológica de Jean Piaget, que vai na direção de censura à validade dos conhecimentos oriundos da filosofia.

Adiantando parte das discussões e pensando na estrada ladrilhada por Platão, desde a invenção do seu Mito da Caverna, cada vez mais atual em meio a infodemia contemporânea, parece que ainda cabe ainda à filosofia um papel crucial na atualidade: crivar tanto a doxa quanto a episteme com a reflexão hermenêutica, de modo a superar seu núcleo mágico de explicação e interpretação da realidade.

\section{Algumas notas sobre o methodus como caminho já percorrido: problemas hermenêuticos}

Desde que os gregos construíram os princípios da ciência ocidental, especialmente Aristóteles, explicitados nos Analíticos anteriores, quando apresenta sua teoria do silogismo, o órganon, enquanto acesso ao conhecimento "verdadeiro", incorporou na modernidade um ethos de "caminho para a verdade". É aliás, em Francis Bacon, embora crítico severo do silogismo aristotélico, que a ideia de Novum Organum [que tem o sugestivo subtítulo Verdadeiras Indicações Acerca da Interpretação da Natureza] se estabeleceu como via ou caminho seguro para o "domínio da natureza", que apresenta como Verum via nostra et ratio ["O nosso plano e o nosso verdadeiro procedimento"]. (BACON, 2003, p. 63).

Queriam os fundadores da ciência ocidental, distantes no tempo, porém imbricados por quase dois mil anos, que a humanidade alcançasse um nível de conhecimento superior, destituído de toda subjetividade, e que fosse rigorosamente testado, seja pela prova silogística ou empírica, ou ambas. Adorno e Horkheimer captaram bem esse afã - quase neurótico - pela instituição da racionalidade irrestrita que quer dominar o mundo e submetê-lo ao seu funcionamento. $O$ método virou obsessão na medida em que "O saber que vence a superstição deve imperar sobre a natureza desencantada" e "O que não se submete ao critério da calculabilidade e da utilidade torna-se suspeito para o esclarecimento." (ADORNO; HORKHEIMER, 2006, p. 18-19). Mas, por essas contradições da história, eis que na sua implacável luta 
contra os ídolos de toda sorte (da tribo, da caverna), o insuspeitado novo organum acabou se convertendo no seu oposto: o próprio mito.

Nessa mesma linha de crítica obsessiva do método seguro e da verdade infalível, apoiando-se no ceticismo aberto por Nietzsche, Gadamer (2014, p. 58) aponta para o recorrente fanatismo do pensamento científico moderno. Em Verdade e Método II, afirma o seguinte: "Na verdade, a ciência tem algo em comum com o fanático: porque ela constantemente exige e dá demonstrações, acaba sendo tão intolerante quanto ele. Ninguém é mais intolerante do que aquele que quer comprovar que aquilo que ele diz deve ser a verdade".

Mas como até hoje não houve vencedor neste infinito debate, e ninguém amealhou a prioridade da razão, nem do caminho para se chegar ao seu santo graal, parece prudente, neste ponto, seguir o conselho de um anarquista metodológico bem humorado, Paul Feyerabend, que assombrou a Academia com o seu Contra o Método [1975], livro em que defendeu o pluralismo metodológico e chocou a comunidade científica com a sentença que abre a introdução da sua obra: "A ciência é um empreendimento essencialmente anárquico" e, na sequência, escandalizou ainda mais dizendo que "O único princípio que não inibe o progresso é: tudo vale." (FEYERABEND, 1977, p. 9).

Imaginemos o impacto dessas afirmações sobre a comunidade científica em pleno auge do Positivismo Lógico do círculo de Popper e depois do sucesso estrondoso do livro de Thomas Kuhn, A estrutura das Revoluções científicas (1997). Porém, o que poderia servir de anátema, por essas contradições da história, reverteuse em favor de seu autor, como ele mesmo disse: "Um pluralismo deste tipo já foi chamado de irracional e excluído da sociedade respeitável; entrementes, tornou-se moda." (FEYERABEND, 1996, p. 179).

Talvez haja nessa passagem uma indelével marca de Nietzsche (2008, p. 282) quando se refere à verdade, no aforismo 540 de $A$ vontade de poder. "Há muitos olhos. Também a esfinge tem olhos: consequentemente, há muitas 'verdades', e, consequentemente, não há nenhuma verdade". Aliás, em sua autobiografia Feyerabend (1996, p. 58) admite a forte impressão que the causou a leitura do Zaratustra, de Nietzsche (1983), tendo se "rendido a sua retórica". E é certo de que 


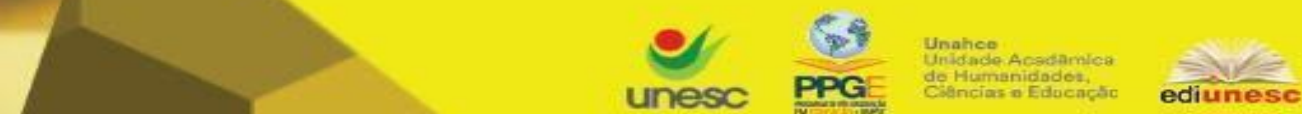

Criar Educação, Criciúma, v. 9, ํㅡ, Edição Especial 2020.- PPGE - UNESC - ISSN 2317-2452

quem leu Assim falou Zaratustra, nunca mais verá o mundo e as coisas do mesmo jeito. Talvez Feyerabend visse a ciência como esfinge, com seus múltiplos olhos, mas nunca de modo irracional, postura que nunca defendeu.

Mesmo correndo aqui o risco de reducionismo do pensamento de Feyerabend e levando-o ao limite, sua perspectiva epistemológica parece dizer que em ciência o que se tem é um horizonte hermenêutico de interpretação, e o que se faz é contar uma história, uma narrativa, nem melhor nem pior do que outras (mito ou religião), apenas diferente, sob outro logos. Aliás, é o que ele faz quando apresenta o seu principal livro [dedicado em memória ao amigo Imre Lakatos], que é considerado uma das importantes narrativas de epistemologia do século XX, como se fora uma missiva despretensiosa:

A origem do ensaio explica o seu estilo: trata-se de uma carta, longa e muito íntima, escrita para Imre e cada frase perversa que contém foi escrita antecipando frase ainda mais ferina de meu companheiro. Também é claro que o livro, como se apresenta, está lamentavelmente truncado. Falta-lhe a parte mais importante, a réplica da pessoa para quem foi elaborado. Publico0 , entretanto, como testemunho da forte e estimulante influência que Imre Lakatos exerceu sobre todos nós. (1977, p. 7)

É mesmo possível que o caso seja de deduzir, do conjunto da obra de Feyerabend, que o órganon científico é mais caminho (no sentido de percurso) do que método (no sentido de regra). É mais andança e errância do que certeza e descanso. E se tudo vale - como contramétodo e caminho multifurcado para as ciências naturais, tradicionalmente mais presas às mitologias científicas (ADORNO; HORKHEIMER, 2006), abre-se uma constelação - para usar um arcano benjaminiano - de possibilidades para as ciências sociais ou ciências do espírito, como as chama Gadamer (2014) [termo herdado de Dilthey].

Nesse sentido errático, para Walter Benjamin, método é também caminho, mas "[...] é caminho não direto" (2016, p. 16), caminho desviante e fragmentário. Dessa forma irregular, o caminho de pesquisa se faz ao pesquisar, sem que o peregrino fique acorrentado a regras demasiadas, a não ser a de contar com franqueza sua história, ser honesto na sua contação ou, como dizia Imre Lakatos (1989, p. 12), manter a "honestidade intelectual". Isso é bem ao contrário do 
indutivismo positivista, pois não é nem uma viagem solitária do cogito, nem uma manifestação empírica da natureza ou do fenômeno; é uma marcha com os outros da pesquisa, seus interlocutores acadêmicos, seus sujeitos narradores, enfim, suas fontes; além de ser, com todas as consequências que isso demanda, como diria Nietzsche (2007), o andarilho e sua sombra.

Mas tal pressuposto tem lá suas implicações epistemológicas, pois noções como indução, dedução e objetividade necessariamente são forçadas a ceder lugar à compreensão hermenêutica, enquanto epifenômeno do ser-precisamente-assim do que se pretende investigar.

Na sua crítica à tentativa de absolutização do método indutivo no âmbito das ciências humanas, Gadamer censura esse procedimento no seu influente livro Verdade e Método I [1960], dizendo que "[...] o que se denomina método na ciência moderna é uma e a mesma coisa por toda parte é só se caracteriza como exemplar nas ciências da natureza", para em seguida concluir emblematicamente - na linha de Feyerabend - que "[...] não existe nenhum método próprio para as ciências do espírito." (GADAMER, 2014, p. 42).

Ao fim e ao cabo, é justo pensar que o que ocorre nas ciências humanas são empreendimentos hermenêuticos possíveis, ajustáveis ao tipo de investigação; mas com o cuidado, como disse Ricoeur (1978), de sermos relacionistas e não relativistas. No relacionismo, podemos hibridizar metodologias, teorias e procedimentos, enquanto no relativismo tudo cabe à moda de ecletismo. E como sabemos pelo apóstolo Paulo na sua Epístola aos Coríntios [6:12], "Tudo me é lícito, mas nem tudo me convém”. Nesse contexto de discussão, o gesto hermenêutico se apresenta como possibilidade relacional.

Avançaremos, na sequência, em alguns pressupostos da hermenêutica moderna, baseando-nos em dois autores que discutem bem de perto essa questão: Hans-Georg Gadamer e Paul Ricoeur, suspendendo aqui prováveis vieses discordantes dos autores, que encontram unidade no procedimento metodológico hermenêutico.

Ainda que não possamos discuti-lo aqui, dados os limites do texto, incluímos Benjamin na tradição da hermenêutica contemporânea, embora com um viés 
diferenciado dos demais autores citados pela sua fragmentariedade, pela concepção de método como desvio e pela procura dos rastros, pormenores e limiares do fenômeno. Para as possibilidades de interpretação de uma hermenêutica fragmentaria em Benjamin, sugerimos a leitura de Ventura (2019).

\section{A hermenêutica como virada epistemológica: Gadamer, Ricoueur e Benjamin}

Embora o termo virada linguística tenha se popularizado a partir da antologia publicada, em 1967, pelo filósofo americano Richard Rorty, intitulada The Linguistic Turn. Essays in Philosophical Method, o giro hermenêutico na filosofia e nas ciências humanas é um processo bem mais antigo, que tanto Gadamer quanto Ricoeur localizam mais precisamente no Romantismo do século XVIII, e demarcam no historicismo alemão suas raízes mais sistemáticas, tais como em Schleiermacher e Dilthey.

Abro aqui um parêntese importante para recuar essa origem ao barroco italiano, precisamente a Giambatista Vico, professor de retórica na Universidade Régia de Nápoles, entre o final do século XVII e início do XVIII, que não só deu origem ao historicismo, enquanto concepção de centralidade da história na compreensão do homem e do desenvolvimento humano [lembremos que o subtítulo de Princípios de uma Ciência Nova: acerca da natureza comum das nações], mas que abusa da metodologia hermenêutica e dos recursos da tradição humanista da eloquentia para constituição da sua grande obra - em franca oposição à solidão do cogito cartesiano. Essa não é somente uma questão de retomada historiográfica, mas de origem, sobretudo quando se vê na principal obra de Gadamer (2014, p. 61), Verdade Método I, um tributo ao trabalho original de Vico no campo hermenêutico, afirmando que "[...] muita coisa do que nos irá ocupar já ressoa em Vico". É aliás, por via de Herder, autor seminal do historicismo alemão, que Vico é recuperado e preservado, chegando à tradição do pós-romantismo e, dessa forma, até Gadamer.

Feita essa importante digressão, podemos voltar às origens da hermenêutica, de acordo com Gadamer e Ricoeur, ainda que por atalhos, para não estender muito a discussão de fundo. 
Embora a hermenêutica remonte à tradição medieval, ligada à exegese de interpretação de textos teológicos e servindo como recurso retórico dos intérpretes [a Retórica é uma das três disciplinas do Trivium, junto com a Gramática e a Lógica], essa é ainda a hermenêutica clássica que "[...] coloca em jogo o problema geral da compreensão [...] é o discurso significante que é hermeneia, que 'interpreta' a realidade, na medida mesma em que diz 'algo de alguma coisa'." (RICOEUR, 1978, p. 8, grifo do autor). Ainda segundo Ricoeur, a virada na compreensão da hermenêutica se dá com Dilthey, mentor de Heidegger, e por essa via chega a Gadamer. É com o primeiro que "[...] o problema hermenêutico se torna um problema filosófico." (RICOEUR, 1978, p. 9). Mas enquanto problema filosófico, a hermenêutica de Dilthey permanece um problema epistemológico, ou seja, ainda persegue uma discussão acerca do sujeito do conhecimento e sua dependência do método científico, inserindo-a no debate de constituição das ciências humanas, sob influxo das ciências naturais. É justamente essa concepção de hermenêutica, por assim dizer, epistemológica, que vai ser colocada em xeque e criticada por Heidegger e aprofundada por Gadamer.

A partir de Heidegger, há uma segunda virada para a compreensão da hermenêutica, que deixa de ser epistemologia para se tornar ontologia, "[...] porque, ao romper com o debate de método, refere-se, de imediato, ao plano de uma ontologia do ser finito, para aí encontrar o compreender, não mais como um modo de conhecimento, mas como um modo de ser." (RICOEUR, 1978, p. 9, grifo do autor). De modo que a questão original da epistemologia, que surge com os clássicos gregos e que invade a modernidade, a saber, é a do sujeito frente ao conhecimento, transforma-se numa pergunta sobre o ser e suas possibilidades de conhecer sendo. Ricoeur coloca, assim, a questão: "[...] o que é um ser cujo ser consiste em compreender? O problema hermenêutico torna-se, assim, um domínio da analítica desse ser, o Daisen, que existe compreendendo. (1978, p. 10, grifo do autor).

É a partir dessa inversão que tanto Ricoeur quanto Gadamer, cada a um a seu modo, vai fundamentar os princípios e os pressupostos de uma nova hermenêutica que influenciará decisivamente diversas áreas das ciências humanas, dando origem a um fenômeno que, por falta de definição, vou chamar aqui de 
hermenêuticas (no plural). Essa compreensão inaugura a era da "virada linguística", que parece seduzir a muitos quando desloca a questão do método, do sujeito, para se propor ao debate da questão da interpretação do ser, do discurso, do texto, da linguagem.

É preciso considerar, no entanto, que o processo histórico de redefinição da hermenêutica evidentemente não ocorreu per si, mas a partir da estrada aberta por desbravadores de descentramentos ou desencaixes (GIDDENS, 2002), tais como Marx, Freud e Nietzsche.

Em que pese uma certa restrição à episteme em Gadamer [que adota uma espécie de veto de Heidegger], apontada por Ricoeur como uma antinomia irresolvível na consideração do modelo interpretativo da hermenêutica, enquanto ontologia ou epistemologia, esse processo levou a um caminho de volta ao órganon, mas agora ressignificado e de certa forma com anticorpos refratários ao sujeito racionalista do iluminismo e ao objetivismo do método positivista. De modo que, na sociologia, Habermas a chama de hermenêutica crítica; Geertz, na antropologia, a chama de interpretação das culturas; Foucault, em livro homônimo, a denomina de hermenêutica do sujeito; na filosofia, Rorty a vê como diálogo (conversação), dentre outras influências no pensamento contemporâneo.

O problema central colocado pela hermenêutica contemporânea, que também é hermeneia, coloca o problema da compreensão e do discurso que se propõe a explicar aquilo a que se refere.

Todavia, quando transformada em problema filosófico-ontológico, como pode a hermenêutica explicar o ser-aí (Daisen)? Como se pode elaborar uma hermeneia, um discurso explicativo, acerca do ser? Linguagem, essa é a resposta da hermenêutica, pois esta é a forma expressiva do ser, ou seja, aquilo que é se confunde com o que diz ser, já que a compreensão é um modo de ser e não apenas de pensar. Não há, para a hermenêutica, a clássica oposição racional entre sujeito e objeto; 0 sujeito que pensa, só pensa acerca do que é, acerca de sua existência, e sua existência é linguagem. Daí a emergência do imperativo fenomênico do texto, do discurso, como mediador hermenêutico para a interpretação e a compreensão do mundo. 
Para evitar qualquer mal-entendido sobre essa questão e não correr o risco de lançar a hermenêutica num idealismo linguístico, basta assumir que o mundo existe para além do homem enquanto physis, mas que surge a ele enquanto fenômeno, enquanto acontecimento. Assim explica Ricoeur (1978, p. 14): "É antes de tudo - e sempre - na linguagem que vem exprimir-se toda compreensão ôntica ou ontológica"; e é a partir dela que o sujeito dá sentido ao mundo e pode falar dele.

Nesse sentido, não somente os fenômenos da natureza, mas sobretudo os humanos passam a ser interpretáveis. É a vida que passa a ser interpretada, discursada, narrada, cabendo ao empreendimento hermenêutico dar algum sentido de "ser" e "estar" no mundo, muitas vezes de forma inconsciente. A empreitada hermenêutica freudiana se autoatribui essa função, de interpretar a existência a partir de uma narrativa do que move o ser a partir do seu inconsciente e suas pulsões; a de Marx, é construir uma narrativa que o compreende [o ser] como uma existência guiada por ideologias inconscientes e relações de produção, que condicionam a vida do sujeito; Nietzsche, por sua vez, inventa toda uma contação do devir como ocaso da vontade de potência e, portanto, como produção e projeção do desejo, consciente ou não. Esses são meros rabiscos exemplares do quanto o empreendimento hermenêutico se distancia do solilóquio do cogito cartesiano, que propugna o ser como objeto de conhecimento, procurando pelo inobjetivo que constitui o Daisen.

Com esses exemplos, pode-se perceber que a tal "realidade" do ser não é mais do que uma produção da linguagem, do discurso. Nada mais oportuno nesse momento do que relembrar a bela metáfora de Foucault (2008, p. 55) em $A$ arqueologia do saber, que entende os discursos não como meros jogos de símbolos, "[...] mas como práticas que formam sistematicamente os objetos de que falam". Então, se o "real natural" e "real humano" são "formados" por uma produção discursiva, cabe ao procedimento hermenêutico a compreensão e interpretação do que Gadamer chamou desses "textos transmitidos" (GADAMER, 2014, p. 228), pois "[...] é na linguagem que o cosmos, que o desejo, que o imaginário acedem à expressão. Sempre é necessária uma palavra para retomar o mundo e convertê-lo em hierofania." (RICOEUR, 1978, p. 15). 
Numa palavra: nas investigações em ciências humanas temos que nos haver é com a coisa do texto, principalmente quando se quer, de alguma forma, mexer com os discursos dos outros que, por seu turno, já são interpretações. No final das contas, lidamos mesmo é com narrativas, por assim dizer, de segunda mão, pois as originais já são traduções movidas por impressões e imprecisões sobre o ser e suas experiências, seja um texto literário, um documento ou uma entrevista. Neste caso, a hermenêutica é o modus operandi do processo de captura do ser que se manifesta em sua discursividade, pois não se está somente diante de uma hermenêutica clássica, de atribuir um sentido cognitivo a um determinado texto ou problema, mas se trata sobretudo de captar o ser existente, da compreensão ontológica do ser que encontrou um jeito de narrar sua experiência, pois como disse Aristóteles, há muitas maneiras de se dizer o ser, e o que podemos fazer é recontar uma dessas diversas maneiras.

\section{A respeito das Sabedorias e llusões da Filosofia: armadilhas da antifilosofia}

Apresentada a hermenêutica como órganon, enquanto caminho de conhecimento, que guiou nossas reflexões até agora, passamos a analisar um caso particular de vinculação da pesquisa ao mito prometeico da ciência, Jean Piaget, e seu veto ao estatuto de conhecimento à filosofia e, portanto à hermenêutica, por sua carência de comprovação e objetividade.

Numa de suas assertivas, Benjamin (2012, p. 37), comentando a Imagem de Proust, disse que "[...] nem tudo nessa vida é modelar, mas tudo é exemplar". Então, o que queremos buscar no referido livro do criador do construtivismo é, justamente, a exemplaridade da regressão ao mito sempre que o discurso científico se propõe a julgar os demais discursos, colocando-se como tábula rasa de acesso à episteme.

A intenção aqui, longe de ser uma ousada pretensão de esgotamento, é somente anunciar um empreendimento hermenêutico, que tende a aproximar o projeto da Epistemologia Genética da herança positivista de Herbert Spencer e August Comte, enquanto encarnações do projeto de uma época.

Sobre esse tipo de análise hermenêutica, Benjamin alertou que é preciso arrancar a ideia (fenômeno) de um certo contínuo da história para dar sentido a sua 


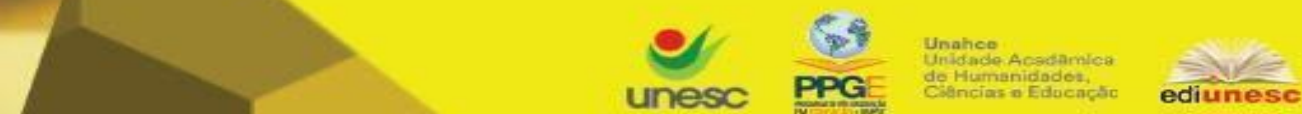

Criar Educação, Criciúma, v. 9, ํㅡ, Edição Especial 2020.- PPGE - UNESC - ISSN 2317-2452

aparição, que ele chama de origem; não no sentido de início, mas como devir. Em uma de suas Teses Sobre o Conceito de História, ele disse que cabe ao historiador materialista, ou seja, ao pesquisador:

[...] ele arranca à época uma vida determinada e, da obra composta durante essa vida, uma obra determinada. O resultado desse procedimento é que assim se preserva e transcende (aufheben) na obra o conjunto da obra, no conjunto da obra a época e na época a totalidade do processo histórico. O fruto nutritivo do que é compreendido historicamente contém, em seu interior, o tempo, como uma semente preciosa, mas insípida. (BENJAMIN, 2012, p. 251, grifo do tradutor)

Aplicando esse princípio ao nosso estudo, a proposta será encontrar na obra (fragmentos, ao menos) de Piaget uma determinada época e um processo histórico que, como disse acima Benjamin, tem o tempo como semente preciosa, mas insípida, dada a longevidade das aspirações cientificistas dos últimos dois séculos.

A elaboração do construtivismo, no conjunto dos esforços de pesquisa do Centro Internacional de Epistemologia Genética, atende ao objetivo de dar à psicologia um caráter científico, retirando-a do limbo subjetivista, atribuindo à epistemologia um estatuto de objeto verificável. Por isso, o distanciamento de Piaget das polêmicas sobre a veracidade do conhecimento, como no caso da condição de refutabilidade, de Popper (1982), ou os paradigmas, de Kuhn (1997). Com esse desvio, a epistemologia piagetiana volta-se para um objeto possível de ser controlado a partir do método clínico, o sujeito cognoscente, que manifesta a exterioridade do conhecimento por meio de um comportamento inteligente. É por essa via que Piaget pretende fundamentar uma teoria científica da ciência de acordo com as ciências naturais, principalmente a biologia. $\mathrm{Na}$ entrevista a Jean-Claude Bringuier, o pesquisador suíço resume assim seu objetivo de pesquisa:

Então, para achar um ponto entre a biologia e a teoria do conhecimento, era preciso estudar o desenvolvimento mental, o desenvolvimento da inteligência, a gênese das noções [...] o estudo dessas transformações do conhecimento, o ajustamento progressivo do saber, é o que chamo de epistemologia genética e que é a única perspectiva possível para um biólogo. (BRINGUIER, 1978, p. 15)

Tal postura representa bem as tendências da psicologia naturalista do final do século XIX, e que invade com força o século XX, como por exemplo no caso de Wundt, 


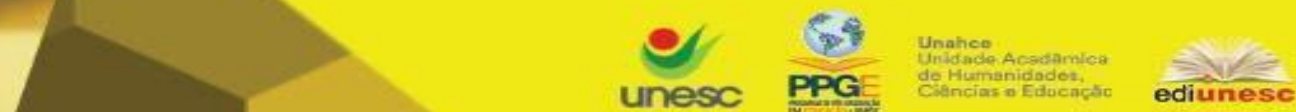

Criar Educação, Criciúma, v. 9, №2, Edição Especial 2020.- PPGE - UNESC - ISSN 2317-2452

cujo principal livro Elementos de Psicologia Fisiológica [1879] dá o tom das pesquisas que adviriam. O plano da investigação tinha como pano de fundo considerar as provas empíricas do desenvolvimento das funções psicológicas superiores verificando-se suas manifestações exteriores, isto é, o comportamento. Nesse rumo, o comportamento inteligente foi considerado o irredutível epistemológico do construtivismo, onde quer que ele se manifeste, como deixou claro Piaget numa passagem da entrevista citada:

J. P. - Minha convicção é que não há nenhuma espécie de fronteira entre o vital e o mental ou entre o biológico e o psicológico. Desde que um organismo tenha consciência de uma experiência anterior e se adapte a uma situação nova, isto se assemelha muito à psicologia. [...]

J-Cl. B. - Entre os girassóis e nós, não há diferença?

J.P. - Não. É a tese central do meu livro Biologia e Conhecimento, onde eu experimento mostrar os isomorfismos. [...]

J. P. - Não! A psicologia não é uma ciência da consciência, é uma ciência do comportamento! Estuda-se o comportamento, incluída nele a tomada de consciência, quando se pode atingi-la, mas quando não se pode, não constitui um problema. (BRINGUIER, 1978, p. 11-12)

É desta forma que a epistemologia pode se transformar numa ciência objetiva, de modo que o conhecimento seja reduzido a um fato, uma coisa a ser pesquisada, sob a rigorosidade do método científico: observação, hipótese, experimentação e generalização. Daí a possibilidade de se considerar a psicologia uma ciência natural, buscando suas raízes na biologia.

Entretanto, essa tendência não constituía propriamente uma novidade à época de Piaget, pois tal alquimia já havia sido proposta por, dentre outros, Herbert Spencer, com a finalidade de transformar a psicologia numa ciência natural para fundar, a par com a física celeste, o que Comte (1996, p. 29) chamou de "física social". E a melhor maneira de fazer isso seria transferir para o campo psicológico e sociológico o princípio da evolução e seleção natural das espécies. Anos antes de Darwin ter sistematizado e publicado sua teoria da evolução, Spencer já havia "captado no ar" da época a grande síntese: assim como o homem evoluiu das espécies inferiores, também seria lógico supor que a sociedade obedecesse a esse mesmo princípio de desenvolvimento natural; deste modo, o mecanismo da evolução biológica explicaria, "objetivamente", a evolução da sociedade. 


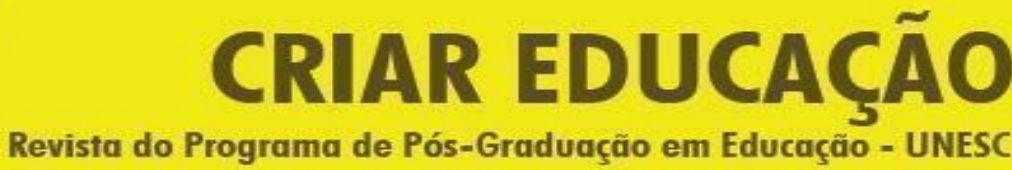

\section{unesc PPGE}

Criar Educação, Criciúma, v. 9, n²2, Edição Especial 2020.- PPGE - UNESC - ISSN 2317-2452

O livro de Spencer, Princípios de Biologia, data de 1827, enquanto o primeiro esboço de A origem das Espécies, de Darwin, só sairia em 1842. Esse oportuno insight de Spencer permitiu a quebra do veto positivista imposto à psicologia, cuja restrição pautava-se na seguinte objeção comteana: "Não podemos estar à janela e ver-nos passar pela rua. No teatro não podemos ser, ao mesmo tempo, ator no palco e espectador na sala." (COMTE, 1996, p. 33). A apresentação da questão, nestes termos, está de acordo com o método das ciências naturais, posto que prevê uma clara e completa distinção entre o pesquisador e objeto pesquisado, condição essa que permitia a Comte advogar a impossibilidade de o homem (pesquisador) estar em dois papéis durante a investigação, o que na sua visão inviabilizaria a "coisificação" do objeto, como fica claro a clássica afirmação do seu Curso de Filosofia Positiva: "O indivíduo pensante não poderia dividir-se em dois, um raciocinando enquanto o outro o visse raciocinar. O órgão observado e o órgão observador sendo, neste caso, idênticos, como poderia ter lugar a observação?" (COMTE, 1996, p. 35).

A saída encontra por Spencer foi se colocar na janela e ver a humanidade passear na rua, adequando seu sistema explicativo às exigências do positivismo. Estava lançado, dessa forma, o aforismo fundamental da psicologia e sociologia spenceriana, comteana e, posteriormente, piagetiana: a ontogênese repete a filogênese.

Muito antes de Piaget, Spencer já usava termos provenientes da biologia em suas explicações psico-sociológicas, tais como "equilíbrio", "adaptação", "regulação" etc.

Vamos a um exemplo:

Uno de los principales descubrimientos de la biologia es que organismos completamente dispares em la edad adulta han sido muy semejantes em los primeiros periodos de su desarrollo e incluso que todos los organismos parten de uma estrutura común. De la misma manera, a pesar de todas las diferencias que acaban por separar a las estructuras sociales desarrolladas, hay uma estrutura rudimentaria de que todas parten. (SPENCER, 1947, p. 8)

Assim, submetendo todo desenvolvimento social às leis naturais da evolução biológica, conclui Spencer (1947, p. 16-18): 


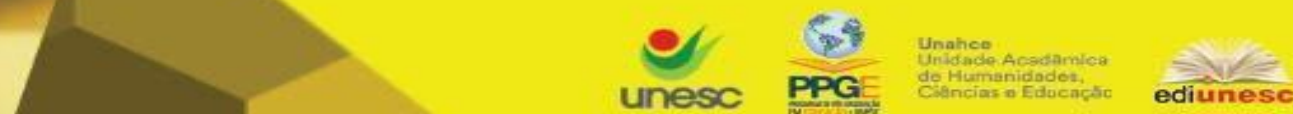

Criar Educação, Criciúma, v. 9, ํㅡ, Edição Especial 2020.- PPGE - UNESC - ISSN 2317-2452

Así como em um organismo animal el progresso de la organización exige, no sólo que se conserve cada uma de las unidades que componen las partes diferenciadas, sino que su descendencia las suceda em sus posiciones, em uma sociedade la constituición de la estrutura se encunetra favorecida por la transmisión de posiciones y funciones a lo largo de las generaciones sucesivas. (...) Uma de las condiciones del progresso social es, como queda dicho, el crescimento de massa, lo qual va acompñado de uma mayor complicación del desarrollo.

Em Piaget, há também submissão da psicologia e da sociologia à biologia, como fica claro na abertura do primeiro capítulo do seu livro Psicologia da Inteligência, quando afirma: "Qualquer explicação psicológica cedo ou tarde acaba por apoiar-se na biologia ou na lógica (ou na sociologia, mas esta, por sua vez, chega à mesma alternativa)." (PIAGET, 1983a, p. 32).

Assim como fizera Spencer, para explicar o surgimento e desenvolvimento das sociedades a partir de analogias com o mundo biológico, Piaget adota a mesma postura para explicar o surgimento e desenvolvimento da inteligência. Segue um exemplo das analogias:

Com efeito, toda relação entre um ser vivo e seu meio apresenta esse caráter específico: o primeiro, em vez de estar submetido passivamente ao segundo, modifica-o ao impor-lhe certa estrutura própria. Ora, psicologicamente acontece o mesmo, exceto que as modificações que então ocorrem não são de ordem substancial, mas exclusivamente funcional, e são determinadas pela motricidade, pela percepção ou pela conjugação de atividades reais ou virtuais (operações conceptuais). (PIAGET, 1983a, p. 13, grifo nosso)

Uma das consequências da submissão do projeto de construção da Psicologia Genética ao método das ciências naturais foi o veto imposto ao estatuto epistemológico da filosofia, ou seja, sua aceitação como conhecimento válido.

Em Sabedoria e llusões da Filosofia, escrito em 1968, Piaget retoma o legado comteano de expulsar toda especulação do âmbito das ciências. Se em Comte ainda encontramos um lugar para a filosofia, no reino das ciências positivas, em Piaget, ela é exilada para o campo dos "saberes", da mera "doxa". As suas conclusões poderiam nos remeter às grandes lutas pela afirmação do novo conhecimento que se contrapôs ao conhecimento teológico da escolástica, enquanto expressão teórica do modo feudal de se viver, não fosse a extemporaneidade dessa polêmica, no crepúsculo dos anos de 1960. O novo conhecimento, isto é, a ciência, encabeçada no campo das 
ideias por Bacon, Descartes, Galileu e outros, tinha lastro material no modo de ver e viver o mundo de uma classe, a burguesia, cuja característica revolucionária consistiu no domínio do mundo material. A despeito do que pode conceber o pensamento idealista, a ciência não nasceu nas universidades ou escolas; pelo contrário, nasceu nas caravanas e em navios mercantes e, muitas vezes, apesar dos intelectuais da época. Foi a necessidade de garantir o trânsito da mercadoria que fez nascer 0 controle empírico dos fenômenos e sua demonstração lógica. Naquele momento, a afirmação da ciência se tornou uma luta árdua, renegando os cânones da escolástica e suas explicações e especulações aristotélicas. Entretanto, realizadas suas várias revoluções no campo material e das ideias, a burguesia se converteu de classe revolucionária em reacionária, metamorfoseando-se, atualmente, em uma nova escolástica. Estão aí as doutrinas decadentes da livre concorrência, do estado mínimo, da "mão invisível" etc. que, em contradição com o movimento sociometabólico do capital financeiro contemporâneo, reafirma o seu descompasso histórico.

Depois de convertida em meio de produção burguês (BERNAL, 1975), a ciência, que um dia foi revolucionária, converteu-se sistematicamente em escolástica, recebendo críticas de todos os flancos. E nisso reside, assim cremos, a extemporaneidade das críticas de Piaget endereçadas à filosofia, cujo apoio central é a mítica infalibilidade do conhecimento científico. Isso se evidencia na medida em que, para ele, o conhecimento verdadeiro e, portanto, a ciência, repousa sobre fatos possíveis de serem controlados e demonstrados; não há espaço para mera conjectura, nem possibilidade, pois se trata do estágio mais evoluído do pensamento humano. Assim como entendia Comte, para Piaget, a ciência é o estágio de maturidade intelectual da humanidade - "estágio positivo do conhecimento" (COMTE, 1996, p. 22) -, sendo sua missão principal a posse da verdade (e também o seu objeto). Já o objeto da filosofia, segundo Piaget (1983b, p. 333), seria a "sabedoria", por assim dizer, o bom senso do filósofo em "tomada de posições" diante dos fatos, uma crença e nunca a explicação desses fatos ou fenômenos. Decorre dessa lógica, que a filosofia é um estágio inferior do pensamento, uma pré-ciência, cabendo ao filósofo decidir-se se quer ascender intelectualmente e tornar-se um homem de ciência ou permanecer na sua fé. Caso decida afirmativamente, precisa abdicar da pura 
especulação e atingir "as verdades demonstráveis" (1983, p. 334) por meio da experiência, reino onde os fatos falam por si em situações de controle.

Levando em consideração que "pode haver muitas sabedorias, mas só uma verdade" (PIAGET, 1983b, p. 334), para o pesquisador genebrino, o filósofo desconfia, especula, mas só o cientista detém a posse da verdade, sendo absurda a pretensão da filosofia em rivalizar com a ciência na descoberta da verdade.

Acentuando suas convicções, mais acerca das ilusões do que das sabedorias da filosofia, Piaget surpreendentemente evoca fragmentos de um filósofo, fazendo das palavras de Karl Jaspers as suas próprias conclusões: "A essência da filosofia é a pesquisa da verdade e não sua posse, mas que trai a si própria, como acontece muitas vezes, até degenerar em dogmatismo, em um saber posto em fórmulas [...] fazer filosofia é estar em caminho." (PIAGET, 1983, p. 335, grifo do autor).

Sua conclusão, na mesma passagem, é a seguinte: "São essas traições da filosofia por ela mesma que sem cessar nós discutimos, não a filosofia como tal." (PIAGET, 1983b, p. 335). Decisivamente, a filosofia só é suportável enquanto procura a verdade, deixando de ser se eventualmente a encontra, o que revelaria a tal traição.

Por contradição, como um bom filósofo sofista, Piaget subverte o sentido da filosofia de Jaspers, submetendo o filósofo alemão ao seu juízo de verdade, pois em ambos pensadores a conotação é bem diversa. Para Jaspers (1971, p. 18), segundo ele próprio, "[...] no mundo, a verdade está em conflito perpétuo", isto é, não existe verdade com "V" maiúsculo e absoluta, estática, porque o conflito enseja sempre novas versões explicativas do mesmo fato. É igualmente questionável que em Jaspers haja apenas a busca da verdade, como trabalho infinito de Penélope. Talvez seja o caso de verificar melhor outra afirmação no mesmo livro em que Piaget retira esse fragmento, quando Jaspers (1971, p. 18) diz que "o filósofo vê a verdade revelar-se a seus olhos". Mas parece que segundo esse autor, é uma verdade relativa, provisória, parcial, já que na mesma passagem ele diz que "[...] a filosofia busca a verdade nas múltiplas significações do ser verdadeiro segundo os modos do abrangente". Nessa mesma obra, parece que Jaspers (1971, p. 19) se volta contra o pensamento de Piaget, pois é importante não esquecer que "[...] a antifilosofia é uma filosofia" e, tanto 
pior, "[...] aspira a verdade total, que o mundo não quer". Certamente, esse último não seria um pressuposto que Piaget endossaria.

Entretanto, se considerarmos, como disse Marx (1984, p. 208) em uma das Teses sobre Feuerbach, que "[...] o debate sobre a realidade [verdade?] ou irrealidade de um pensamento isolado da prática é um problema puramente escolástico", não pretendemos insistir nas polêmicas conclusões de Piaget contra a filosofia, nem tampouco apresentar razões de estado contra as sabedorias e ilusões da ciência, cujo escrutínio do mito revelado foi exaustivamente explicado por Adorno e Horkheimer, na Dialética do Esclarecimento.

A intenção, nos limites deste artigo, foi apenas destacar esse modo [mítico?] de ver o conhecimento.

\section{Sob pena de não poder concluir}

Ao restituir o projeto deste artigo, nessas observações finais, nos sentimos como Foucault (1996, p. 79) na aula inaugural do College de France, em 2 de dezembro de 1970, e "[...] compreendo melhor porque eu sentia tanta dificuldade em começar, há pouco". A dificuldade tem a ver com os perigos de ressurgência do mito diante do pavoroso momento pandêmico atual, enquanto explicação da conturbada realidade que aflige a pobre humanidade.

A dificuldade consiste na constatação de que nos tornamos cada vez mais pobres em experiências comunicáveis, como aquelas que Benjamin constatou ocorrer na mudez do ex-combatentes da primeira guerra. Tal como sob os canhões de artilharia e rajadas de bombardeios aéreos, encontramo-nos novamente subjugados na guerra contra a Pandemia da Covid-19, e continua exposto "o frágil e minúsculo corpo humano." (BENJAMIN, 2012, p. 214).

Embora Terêncio, comediante latino dos primeiros séculos, tenha nos lembrado de que nada do que é humano nos deveria surpreender [Nihill a me alienun puto], a humanidade ainda surpreende. Para lembrar, a peça do dramaturgo de onde vem essa frase intitula-se $O$ verdugo de si mesmo, ou seja, aquele que se autoflagela, não sendo, portanto, inoportuno nem insensato lembrar dela no contexto atual. Como se trata de uma tragicomédia, é bem-vinda em um momento em que a reedição do 
mito é duplamente alçado à elemento explicativo do momento presente. De um lado, tem-se o movimento neoconservador, que tenta reeditar - como muito sucesso, digase de passagem - o mito original que, embora desterrado de suas condições materiais originais, renasce esquizofrênico. De outro, a mídia hegemônica reedita o extemporâneo mito prometeico do cientista especialista, num afã de encontrar no discurso da ciência a dose correta de panaceia explicativa que o conturbado e neurótico momento reivindica.

No meio da confusão, resiste a desprestigiada, mas vigilante filosofia, se não para dar as tão esperadas respostas, ao menos para garantir a sua função histórica de fazer perguntas, porque de certezas já estamos bem servidos. A questão é que, de ambos os lados, abundam presságios escatológicos, sejam eles provenientes das religiões neoconservadoras ou dos modelos matemáticos e estatísticos, tão objetivos quanto podem ser objetivas as profecias da ciência.

Assim, infiltradas nos intrincados meandros da infodemia atual, as informações advindas de autoridade religiosas ou científicas fazem ecoar o mito por uma segunda vez; entretanto, para usar uma expressão de Marx (2011, p. 25), a segunda vez é "como farsa".

\section{Referências}

ADORNO, T.; HORKHEIMER, M. Dialética do esclarecimento. Rio de Janeiro: Zahar, 2006.

ARISTÓTELES. Órganon. Trad. Edson Bini. São Paulo: Edipro, 2011.

BACON, F. Novum organum. Versão eletrônica. 2003. Disponível em: < https://edisciplinas.usp.br/pluginfile.php/4344026/mod_folder/content/0/francis_bacon _novum_organum.pdf >. Acesso em: abr.. 2020.

BENJAMIN, W. Obras Escolhidas I, Magia e técnica, arte e política: ensaios sobre literatura e história da cultura. Trad. Sérgio P. Rouanet. São Paulo: Brasiliense, 2012. 
BENJAMIN, W. Origem do drama trágico alemão. Trad. João Barrento. 2.ed. Belo Horizonte: Autêntica, 2016.

BERNAL, J. Ciência na história. v.1. Tradução de António Neves Pedro. Lisboa: Livros Horizonte, 1975.

BRINGUIER, J-C. Conversando com Piaget. Rio de Janeiro/São Paulo: DIFEL, 1978.

COMTE, Auguste. Curso de Filosofia Positiva. Tradução de José Gianotti e Miguel Lemos. Col. Os pensadores. São Paulo: Nova Cultural, 1996.

FEYERABEND, P. K. Contra o método. Rio de Janeiro: F. Alves, 1997.

FEYERABEND, P. K. Matando o tempo: uma autobiografia. Tradução Raul Fike. São Paulo: UNESP, 1996.

FOUCAULT, M. A arqueologia do saber. Rio de Janeiro: Forense Universitária, 2008.

FOUCAULT, M. A ordem do discurso: aula inaugural do Colege de France, pronunciada em 02 de dezembro de 1970. Tradução de Laura Fraga de almeida Sampaio. São Paulo: Edições Loyola, 1996.

GADAMER, H.-J. Verdade e método I. Trad. Flávio Paulo Meurer. 14.ed. Petrópolis/RJ: Vozes, 2014.

GIDDENS, A. Modernidade e identidade. Rio de janeiro: Zahar, 2002.

JASPERS, K. Introdução ao pensamento filosófico. São Paulo: Cultrix, 1971.

KUHN, T. A estrutura das revoluções científicas. 5. ed. São Paulo: Editora Perspectiva, 1997.

LAKATOS, I. La metodología de los programas de investigación científica. Versión española Juan Carlos Zapatero. Madri: Alianza Editorial, 1989.

MARX, K. A ideologia alemã. Teses sobre Feuerbach. São Paulo: Moraes, 1984.

MARX, K. O 18 brumário de Luís Bonaparte. São Paulo: Boitempo, 2011.

NIETZSCHE, F. A vontade de poder. Tradução Marcos Sinésio Pereira Fernandes e Francisco Moraes. Rio de Janeiro: Contraponto, 2008.

NIETZSCHE, F. Assim Falou Zaratustra. Trad. Mário da Silva. Rio de Janeiro: Civilização Brasileira, 1983. 


\section{CRIAR EDUCAÇÃO}

Revista do Programa de Pós-Graduação em Educação - UNESC

Criar Educação, Criciúma, v. 9, n²2, Edição Especial 2020.- PPGE - UNESC - ISSN 2317-2452

NIETZSCHE, F. O viajante e sua sombra. São Paulo: Editora Escala, 2007.

PIAGET, J. Psicologia da inteligência. Tradução de Nathanael C. Caixeiro. Rio de janeiro, Zahar, 1983a.

PIAGET, J. Sabedorias e ilusões da filosofia. Tradução de Zilda de A. Daeir. Col. Os pensadores. São Paulo: Abril Cultural, 1983b.

POPPER, Karl R. Conjecturas e refutações. $2^{\mathrm{a}}$ Edição. Tradução de Sérgio Bath. Brasília: Editora UnB, 1982.

RICOEUR, P. O conflito das interpretações: ensaios de hermenêutica. Tradução Hilton Japiassu. Rio de Janeiro: Imago Editora, 1978.

SPENCER, H. Abreviatura de princípios de sociología. Tradução de Fernando Vela. Buenos Aires: Revista Occidente Argentina Buenos Aires, 1947.

VENTURA, L. O voo da fênix. Florianópolis: UDESC, 2019. 